\title{
The effect of fibre source on the numbers of some fibre-degrading bacteria of Arabian camel's (Camelus dromedarius) foregut origin
}

\begin{abstract}
The total bacterial community of Fibrobacter succinogenes and Ruminococcus flavefaciens in fibre-enriched culture of the foregut contents of 12 adult feral camels (Camelus dromedaries) fed on native vegetation in Australia was investigated using quantitative PCR. Foregut contents were collected postmortem, pooled and filtered before divided into two fractions. One fraction was used for extraction of DNA, while the other fraction was inoculated straight away into BM 10 contained filter paper (FP), cotton thread (CT) or neutral detergent fibre (NDF) as the sole carbohydrate sources in Hungate tubes. The tubes were incubated anaerobically at $39{ }^{\circ} \mathrm{C}$ for 1 week. After a near complete degradation of the FP and CT and extensive turbidity in the NDF, media subculturing was carried out into fresh media tubes. This was repeated twice before genomic DNA was extracted and used for quantification of bacteria. Using an absolute quantification method, the numbers of cells in $1 \mathrm{ml}$ of each sample ranged from $4.07 \times 106$ to $2.73 \times 109$ for total bacteria, $1.34 \times 103$ to $2.17 \times 105$ for $\mathrm{F}$. succinogenes and $5.78 \times 101$ to $3.53 \times 104$ for R. flavefaciens. The mean cell number of $F$. succinogenes was highest in the FP enrichment medium at approximately 107-fold, whereas for the R. flavefaciens targeted primer, the NDF enrichment media had the highest mean cell number at approximately 4 -fold when compared to the rumen content. The data presented here provide evidence of fibre type preference by the two main fibre-degrading bacteria and would help us understand the interaction between fibre type and fibre-degrading microorganisms, which has ramification on camel nutrition at different seasons and environments.
\end{abstract}

Keyword: Fibre-degrading bacteria; Real-time PCR; Arabian camel; Native vegetation 